\title{
DILATED RENAL COLLECTING SYSTEMS: \\ DIFFERENTIATING OBSTRUCTIVE FROM \\ NONOBSTRUCTIVE DILATION USING \\ DUPLEX DOPPLER ULTRASOUND
}

\author{
RONALD O. BUDE, M.D. \\ JOEL F. PLATT, M.D. \\ JONATHAN M. RUBIN, M.D., PH.D. \\ DANA A. OHL, M.D.
}

From the Departments of Diagnostic Radiology and Urology,

University of Michigan Medical Center, Ann Arbor, Michigan

\begin{abstract}
BSTRACT-Two patients with ileal loop urinary diversions, studied with real-time and Doppler mography ("duplex sonography") of the kidneys, were shown to have dilated intrarenal collecting stems. Resistive index measurements calculated from the Doppler signal correctly identified obruetive dilatation in 1 case and nonobstructive dilatation in the other.
\end{abstract}

he role of duplex sonography in the evaluation 7. renal transplants has been documented. ${ }^{1,2}$ hedifficulty in using gray-scale sonography to If erentiate obstructive from nonobstructive bllecting system dilatation in patients predisosed to reflux (often diverted kidneys) is well wown. The recent literature ${ }^{4}$ suggests that uplex sonography can differentiate obstructive

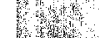

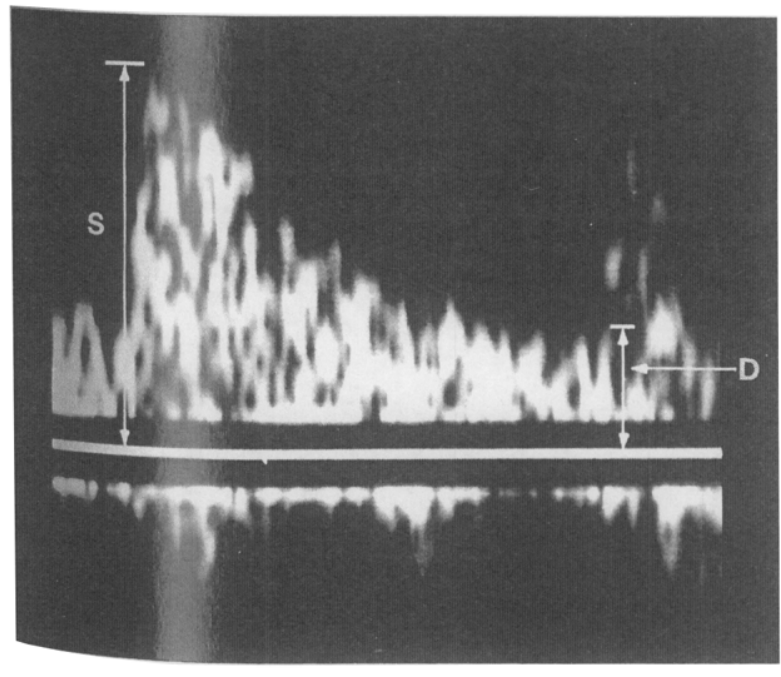

from nonobstructive dilatation in kidneys, using a measurement known as the resistive (or Pourcelot) index ${ }^{5}$ (Fig. 1). We describe the duplex sonographic evaluation of 2 patients with diverted kidneys, one with obstructive and the other with nonobstructive collecting system dilatation.

\section{Case Reports}

\section{Case 1}

A thirty-seven-year-old woman presented to the emergency room. She had a past history of left nephroureterectomy (sixteen years previously) for transitional cell carcinoma, radical cystectomy with ileal loop diversion (five years previously) for invasive transitional cell carcinoma of the bladder, and biopsy-proved sarcoidosis in mediastinal nodes (one year previously). There was a history of right flank pain

Figure 1. Method of obtaining resistive (Pourcelot) index from arcuate artery Doppler profile. RI $=(S-D) / S$, where $S=$ height of systolic peak (to baseline), $D=$ height of diastolic trough (to baseline), and $R I=$ resistive index. 

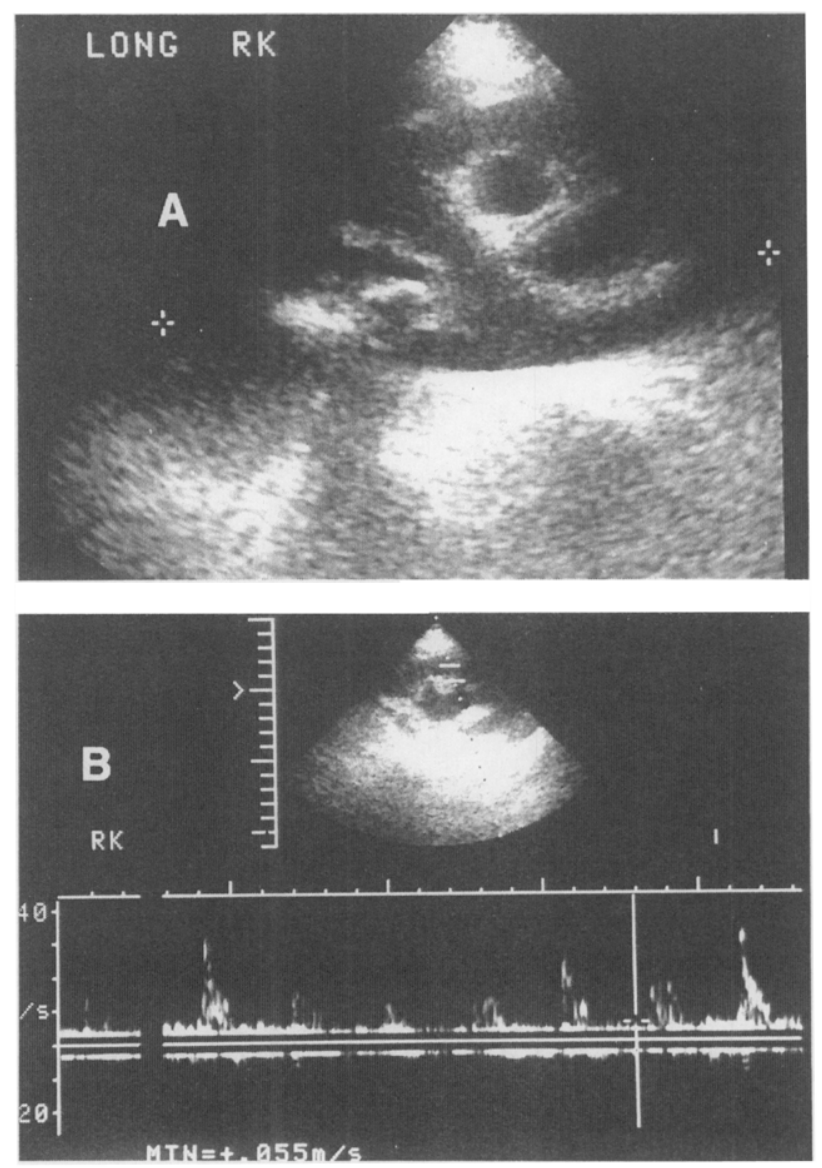

Figure 2. Case 1. (A) Isolated image from right renal ultrasound showing moderate dilatation of collecting systems. Incidental note is made of upper pole calculus (poorly visualized). (B) Doppler profile shows resistive index calculated from this image was 0.88 , compatible with obstruction rather than passive dilatation.

and essentially no urine output from the ileostomy stoma for five hours preceding presentation. At presentation, the creatinine was elevated to 1.4, from a baseline of 0.6. Right renal duplex ultrasound examination at the time of admission showed moderate dilatation of intrarenal collecting systems (Fig. 2A) with an elevated resistive index of approximately 0.88 (Fig. 2B). The findings were thought to represent obstructive rather than passive dilatation. Subsequent loopogram on the same day (Fig. 3) disclosed obstruction by a calculus at the ureteropelvic junction (UPJ)/proximal right ureteral region. Percutaneous nephrostomy placed the same day relieved the obstruction.

Repeat renal ultrasound examination three days after percutaneous nephrostomy showed a nonobstructed right kidney with the resistive index having returned to a normal level of 0.68 (Fig. 4). The patient underwent uneventful ex-
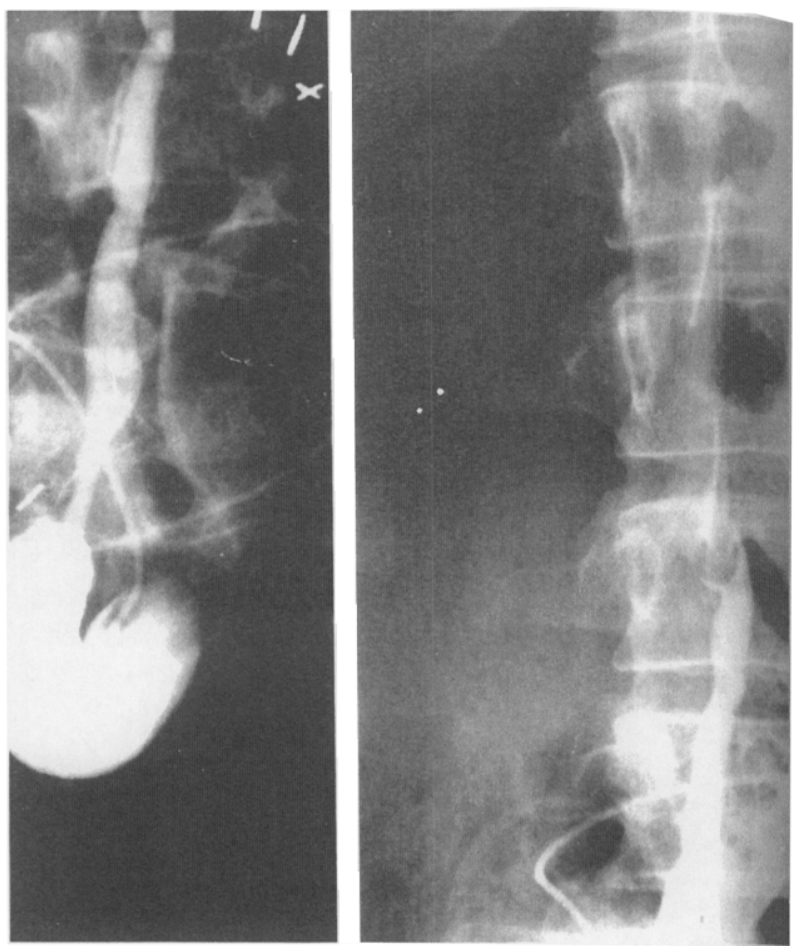

Figure 3. Case 1. Ileal loopogram. On right rat diograph note obstruction of proximal ureter by fill ing defect (consistent with calculus).

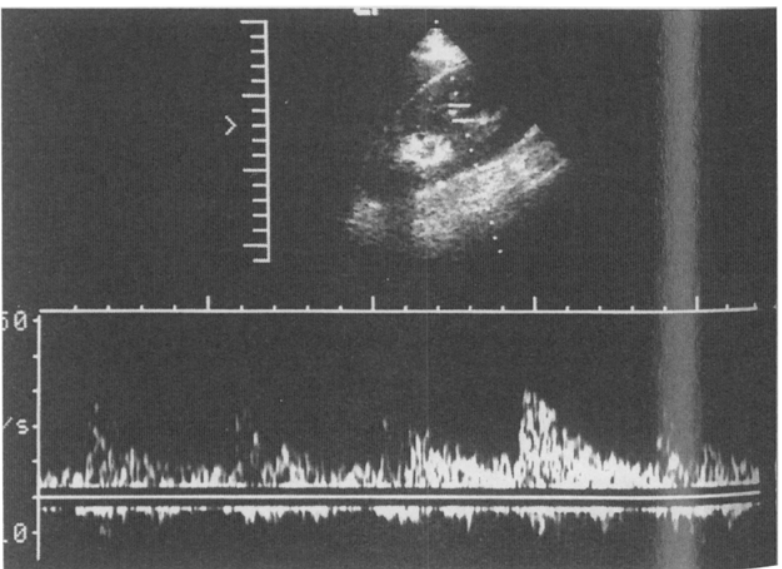

FIGURE 4. Case 1. After relief of obstruction with percutaneous nephrostomy, resistive index (calculated from this image) now normal, measuring 0.68 .

tracorporeal shock-wave lithotripsy and was discharged with an indwelling right percutaneous nephrostomy. The stone fragments later cleared, and the nephrostomy tube was re moved.

\section{Case 2}

The patient is a fifty-six-year-old woman pos pelvic exenteration for bladder cancer, with it eal loop urinary diversion in 1973 . There was a 

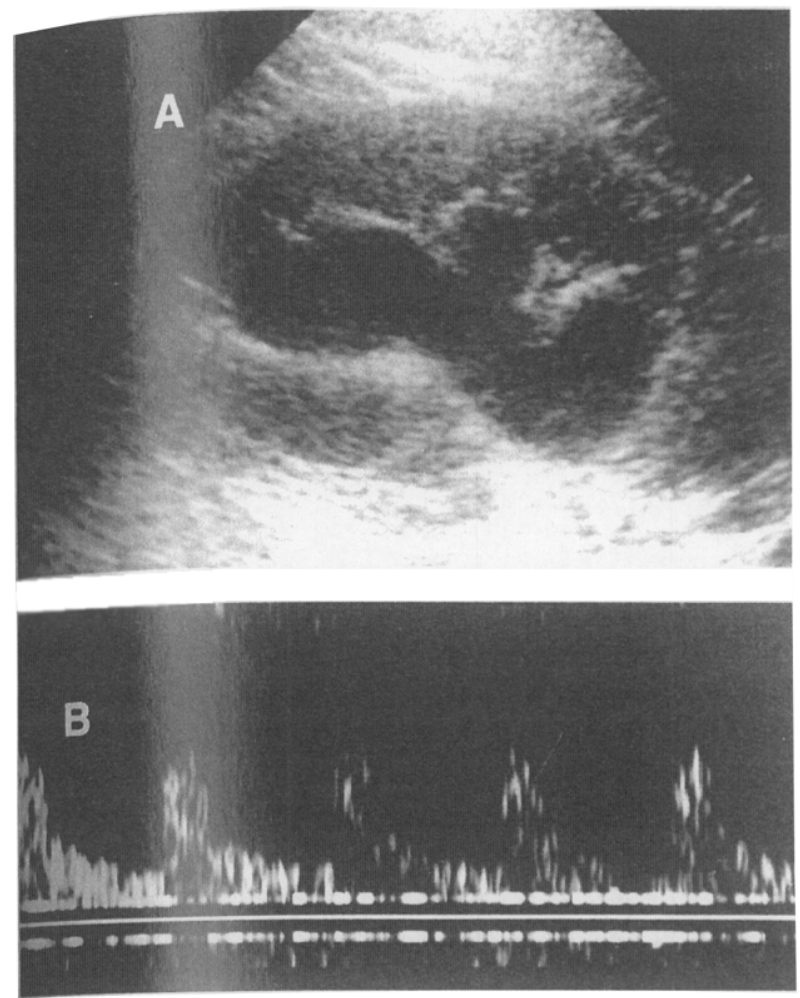

Ficure 5. Case 2. (A) Left renal ultrasound showing moderate dilatation of collecting systems, and (B) normal Doppler US of left kidney, with normal resistive index of 0.66 .

history of struvite stone disease in the past. Thiree weeks before admission for elective left tenal stone removal, renal duplex ultrasound examination (Fig. 5A) showed moderate dilatation of left intrarenal collecting systems, a normal Doppler profile, and a normal resistive index of 0.66 (Fig. 5B). The findings were compatible with passive dilatation, without cvidence of obstruction. Ileal loopograms both at that time and at the time of percutaneous stone removal showed no evidence of obstruction.

\section{Comment}

The difficulty in differentiating obstructive trom nonobstructive intrarenal collecting systhen dilatation in general ${ }^{4}$ and in the ileal loop diverted kidney in particular ${ }^{3}$ is well known. Early animal research has shown that the intrarenal vascular resistance increases secondary to obstruction. ${ }^{6-8}$ The recent literature ${ }^{4}$ suggests that measuring this increased resistance with duplex Doppler sonography, using the resistive (or Pourcelot) index ${ }^{5}$ can distinguish between obstructed and passively dilated collecting systems (Fig. 1). A resistive index of 0.7 appears to be optimal for this distinction, with values less than 0.7 being normal and values greater than 0.7 being abnormal and consistent with obstruction. ${ }^{4}$

In the 2 patients presented here, both with dilated collecting systems in ileal loop diverted kidneys, the resistive index correctly identified obstructed and nonobstructed kidneys. Given these results, as well as those of Platt et al. ${ }^{4}$ it is reasonable to assume that duplex sonography has the potential of becoming a primary method (and in some cases the only method) for differentiating obstructive from nonobstructive dilatation in diverted kidneys.

Department of Radiology, Room 2910
University of Michigan Hospital
Ann Arbor, Michigan 48109 (DR. BUDE)

\section{References}

1. Rigsby CM, et al: Renal allografts in acute rejection: evaluation using duplex sonography, Radiology 158: 375 (1986).

2. Rifkin MD, et al: Evaluation of renal transplant rejection by duplex Doppler examination: value of the resistive index, AJR 148: 759 (1987).

3. Cronan JJ, Amis ES, Scola FH, and Schepps B: Renal obstruction in patients with ileal loops: US evaluation, Radiology 158: 647 (1986).

4. Platt JF, Rubin JM, Ellis JH, and DiPietro MA: Duplex Doppler US of the kidney: differentiation of obstructive from nonobstructive dilatation, Radiology 171: 515 (1989).

5. Nelson TR, and Pretorius DH: The Doppler signal: where does it come from and what does it mean? AJR 151: 439 (1988).

6. Ryan PC, et al: Experimental partial ureteric obstruction: pathophysiological changes in upper tract pressures and renal blood flow, J Urol 138: 674 (1987).

7. Murphy GP, and Scott WW: The renal hemodynamic response to acute and chronic ureteral occlusions, J Urol 95: 636 (1966).

8. Vaughan ED, Sorenson EJ, and Gillenwater JY: The renal hemodynamic response to chronic unilateral complete ureteral occlusion, Invest Urol 9: 78 (1970). 